\title{
Experimental Study of Polyurethane-Based Fuels with Addition of Paraffin and Aluminum for Hybrid Rocket Motors
}

\author{
Susane Ribeiro Gomes¹, Leopoldo Rocco Junior¹, José Atílio Fritz Fidel Rocco ${ }^{1}$ Koshun Iha
}

\begin{abstract}
Experimental investigation was conducted to determine the relative propulsive and combustion behavior of several polyurethane-based solid-fuel formulations containing $30 \% \mathrm{w} / \mathrm{w}$ of paraffin or $10 \%$ of aluminum powder. In total, seven solid-fuel formulations were investigated, four containing $30 \%$ of paraffin and three with 10\% of aluminum. The polyurethane was synthesized with pre-polymer technology. The oxidizer was gaseous oxygen, which was forced into the combustion chamber with axial and swirl methods. Firing tests with 7 configurations were performed. Thrust measurements indicated that the addition of paraffin increased thrust at about $57 \%$ and regression rates at about $70 \%$. No relevant improvement in performance was obtained with aluminum addition. Specific impulse decreased when aluminum particles were added to the fuel. The mixture that produced the best ballistic parameters was polyurethane plasticized with castor oil and 30\% $\mathrm{w} / \mathrm{w}$ of paraffin with gaseous oxygen injected through a swirler.
\end{abstract}

KEYWORDS: Hybrid rocket motor, Aerospace propulsion, Rocket motors.

\section{INTRODUCTION}

Hybrid rocket engine (HRE) is a type of rocket motor that combines the advantages of both solid and liquid fueled rockets and avoids many of the underperformances. In a hybrid, the oxidizer is stored as liquid or gas in tanks and the fuel is stored as solid-fuel grain in the combustion chamber. Oxidizer is injected over the burning fuel surface, and the resulting gases are expelled out of a nozzle to produce thrust. Because the fuel and oxidizer are separate, and cannot easily mix (because they are at different phases), hybrid rockets have very little danger of exploding (Boardman, 2001). Hybrids may provide higher $I_{\mathrm{sp}}$ than solid motors, and due to the high-density solid, they may present higher densityspecific impulse than liquid engines. Advantages such as fuel versatility - additives can be easily embedded in the fuel grain - potential environmental friendliness, and low cost due to high levels of safety and minimal failure modes are widely acknowledged. Classical hybrid rocket motors also present disadvantages yet to overcome, such as combustion inefficiencies due to poor mixing and mixture ratio shifting and mainly low regression of the fuel grain (Altman, 2001). Several methods for improving regression rates have been proposed and investigated. Approaches to increase regression rates usually employ advanced fuels into three categories:

- Addition of energetic particles: A methodology to increase the regression ratein HREshas been to introduce aluminum into the solid fuel (Chiaverini, 2007). At Penn

三 1.Instituto Tecnológico de Aeronáutica - São José dos Campos/SP - Brazil

Author for correspondence: Susane Ribeiro Gomes | Instituto Tecnológico de Aeronáutica | Praça Eduardo Gomes, 50 | CEP $12.228-901$ São José dos Campos/SP - Brazil | Email: susaneribeiro@gmail.com

Received: 21/01/13 | Accepted: 19/06/13 
State University, nanosized particles of aluminum powder with diameters of $70-150 \mu \mathrm{m}$ were mixed into hydroxyl-terminated polybutadiene (HTPB) fuel grains and tested (Chiaverini et al., 2000; Evans et al., 2009). The results showed that the regression rates increased by $50 \%$ over the HTPB without aluminum. Researchers at University of Pennsylvania (UPENN) reported improvements of $60 \%$ on regression rate with the use of embedded nanoparticles (Risha et al., 2007).

- Use of energetic polymers instead of conventional fuels such as HTPB; this polymer is widely used due to its strong mechanical and durability properties and the technology is well known due to the use in solid rocket motors (Altman and Humble, 1995; Altman and Holzman, 2007; Geisler et al. 2010).

- Use of paraffin-based fuels due to the inherent masstransfer mechanism. Paraffin Fuels Researchers at Stanford University (Karabeyoglu et al. 2001) discovered that paraffin-based fuels exist which have regression rates that are three to four times than those of conventional hybrid fuels. This is largely due to the development of a thin liquid layer on the fuel grain surface which becomes instable: instability appears due to the incoming oxidizer flow pattern and liquid fuel droplets are injected into the boundary layer (Karabeyoglu et al. 2001; Karabeyoglu and Cantwell, 2002). This enhanced mass-transfer mechanism increases fuel mass flow without the blocking effect typical of gaseous fuel blowing.

Paraffin presents poor mechanical properties; a binder is hence desirable to sustain loads on flight condition. Therefore, the purpose of this work was the development of a polyurethane (PU) binder, or polymeric matrix, with total substitution of HTPB pre-polymer for another polyol, or mix of polyols. This product is supposed to be applicable as a fuel binder or solid propellant binder formulations. The synthesized binder is embedded with paraffin and micron-sized aluminum particles. Synthesized fuels are tested to assess the improvement in combustion efficiency and regression rates.

In addition to developing a potential high regression rate fuel, a second methodology was employed to improve combustion efficiency. Swirling type injectors are known to increase heat transfer from the flame to the grain surface. This method has first-order effects on regression rates (Knuth et al., 1998; Carmicino and Sorge, 2005, 2007).

The swirl injector was used in the second series of tests to evaluate the relative improvement in combustion efficiency and regression rates in comparison to the axial injector. The use of paraffin and swirl injectors yielded improvements in thrust up to $57 \%$, and in regression rates up to $70 \%$ in relation to the standard PU fuel and axial injector.

\section{METHODOLOGY}

This section outlines the steps taken in this work: synthesis of PU pre-polymer, addition of paraffin addition of aluminum particles, and firing tests.

In the binder synthesis, HTPB-hydroxyl-terminated polybutadiene was replaced with a modified polytetramethylene ether glycol (PTMEG) pre-polymer with $4.3 \%$ of free NCO. The mixture was cured with a liquid amine (ETHACURE) and plasticized with castor or mineral oil. Finally, PU elastomers were obtained.

A microcrystalline paraffin from petroleum (Petrobras 140/145-1) composed of saturated aliphatic hydrocarbons with melting point of $61.4^{\circ} \mathrm{C}$ and boiling point of $290^{\circ} \mathrm{C}$, at standard conditions, was added to the synthesized PU. In this work, aluminum particles with diameters of $100 \mu \mathrm{m}$ were added to three chosen fuel combinations in the proportion of $10 \% \mathrm{w} / \mathrm{w}$. Firing tests with axial and swirl injectors were done and the ballistic results were obtained and evaluated. A side view of swirl injector is shown in Fig. 1, and a scheme of the flow entering the combustion chamber is presented in Fig. 2.

\section{EXPERIMENTAL SETUP}

The baseline engine design was developed from a need for simplicity and flexibility; therefore, a modular design was incorporated. The set could be assembled and disassembled in minutes, allowing the practice of several tests per session.

The case and the flanges were made from stainless steel. The case was machined to fit between the steel flanges. The nozzle was adapted in the aft flange, to prevent nozzle escape. A hydraulic system was settled to perform the 


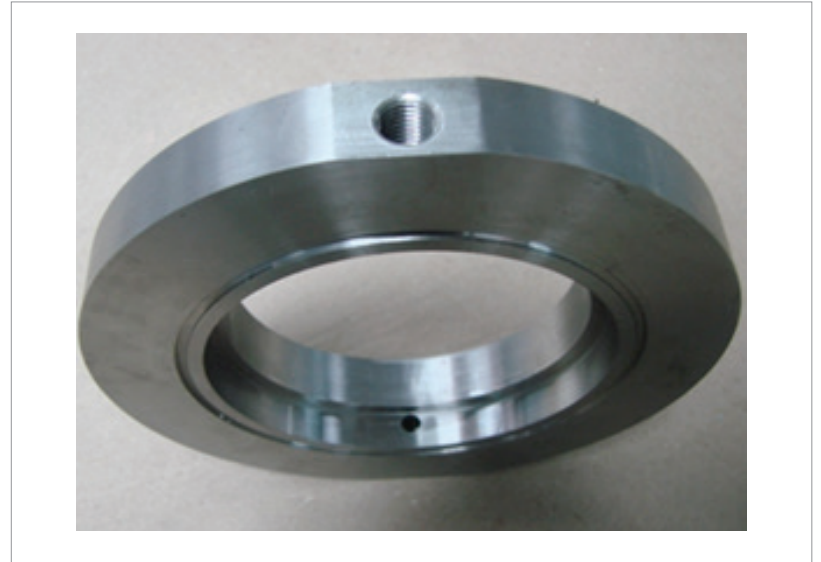

Figure 1. Side view of the swirl injector. The holes are the oxidizer hose entrances.

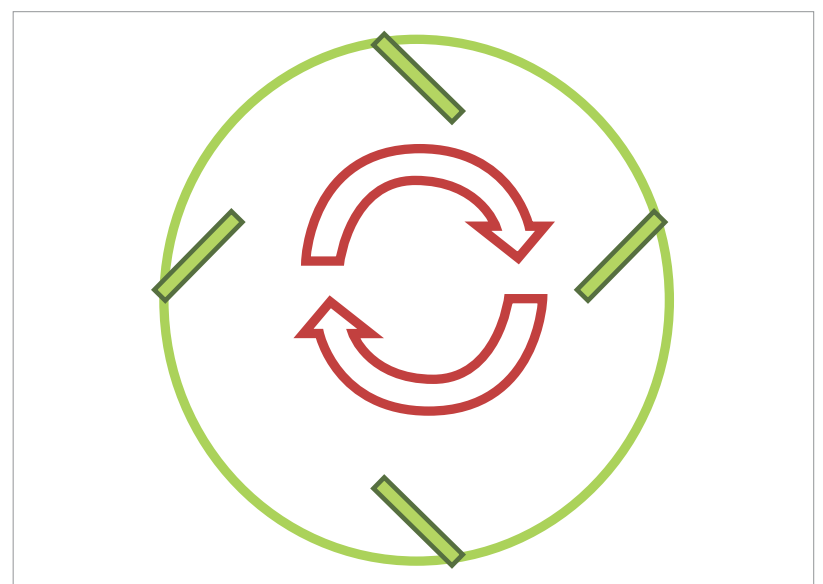

Figure 2. Schematic diagram of the swirl injector cross-section.

thrust measurements. A view of the motor attached to the test bench is shown in Fig. 3. Compression fitting valves were used in the oxygen feed line. A squib was used to achieve ignition.

A schematic diagram of the test facility is exposed in Fig. 4. Compression fitting valves were used in the oxygen feed line. A pyrotechnic method was used to achieve ignition.

The combustion chamber is constructed of $316 \mathrm{~L}$ stainless steel, total length of $215 \mathrm{~mm}$, and inner diameter of $68.3 \mathrm{~mm}$. The fuel grain is $185 \mathrm{~mm}$ long, inner diameter of $20 \mathrm{~mm}$. Pre-chamber is $15 \mathrm{~mm}$ long and post-chamber is $10 \mathrm{~mm}$ long. No thermal isolation was used in this project; it is intended to use a high temperature coating in future work. The experiments were performed in ambient conditions, with temperature of approximately $27^{\circ} \mathrm{C}$ and $1.024 \mathrm{MPA}$ and humidity values varying between 40 and $80 \%$.

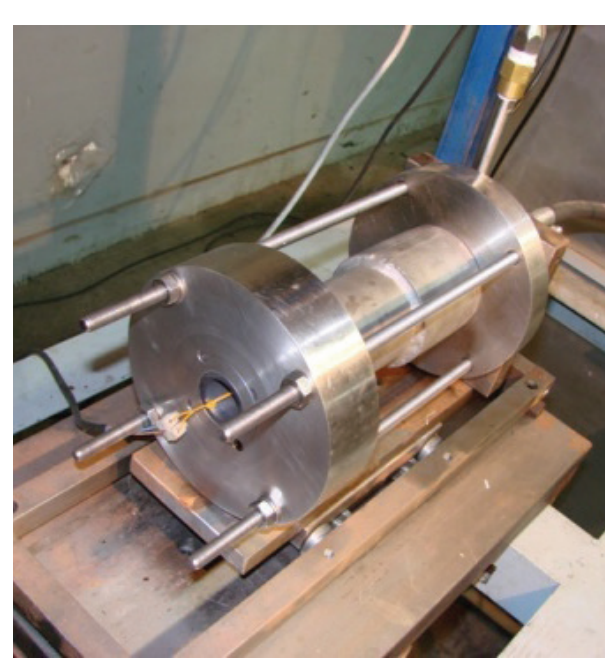

(a)

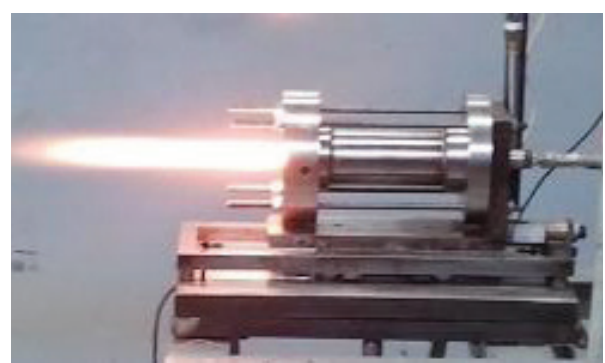

(b)

Figure 3. Side view of the labscale hybrid rocket motor on the test bench (a) and during test (b).

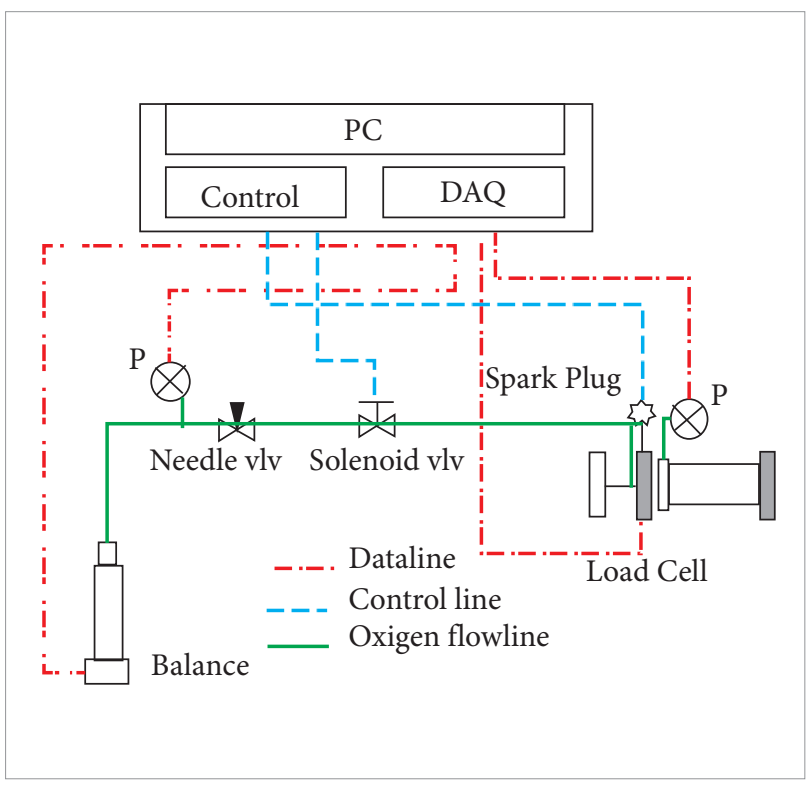

Figure 4. Diagram of the experimental apparatus. 
Nozzle is made of graphite, throat diameter of $8 \mathrm{~mm}$, convergence angle of $30^{\circ}$ and divergence angle of $15^{\circ}$. The length was calculated accounting for the desired exit pressure as close as possible to the ambient pressure.

\section{RESULTS AND DISCUSSION}

Average regression rate is defined in Eq. 1 and oxidizer mass flux is experimentally defined in Eq. 2:

$\dot{r}_{a v g}=a \bar{G}_{o x}^{n}$

$G_{o x}=\frac{\dot{m}_{o x}}{\pi\left(\frac{D_{i}+D_{f}}{2}\right)^{2}}$

Using experimental data, average regression rate is calculated as follows, Eqs. 3 and 4:

$$
\begin{aligned}
& \Delta m=\frac{\pi}{4}\left(D_{2}^{2}-D_{1}^{2}\right) \rho L=\frac{\pi}{4}\left(D_{2}+D_{1}\right)\left(D_{2}-D_{1}\right) \rho L \\
& \dot{r}=\frac{D_{2}-D_{1}}{\Delta t}=\frac{4 \Delta m}{\pi\left(D_{2}+D_{1}\right) \rho L \Delta t}
\end{aligned}
$$

The specific impulse is determined by dividing the total impulse by the weight of the propellant (fuel and oxidizer) consumed. The total impulse is calculated by numerically integrating the thrust over time for the duration of the test using a simple Riemann squares approximation implemented on matlab and then divided by the weight of the propellant used as shown in Eq. 5:

$I_{s p}=\frac{\sum_{i=0}^{i=t_{b}} \frac{1}{2}\left(T_{i+\Delta t}+T_{i}\right) \cdot\left(t_{i+\Delta t}-t_{i}\right)}{g \cdot m_{\mathrm{prop}}}$

where $I_{\mathrm{sp}}$ is the specific impulse, $T_{i}$ is the current thrust value, $T_{i+\Delta t}$ is the thrust at the next time step, $t_{i}$ is the current time, $T_{i+\Delta t}$ is the time at the next time step, $g$ is the acceleration due to gravity, and $m_{\text {prop }}$ is the mass of the propellant consumed during the burn.

The first series of synthesis provided three fuel formulations, the first was plasticized with mineral oil, the second with castor oil, and the third was plasticized with castor oil and embedded with $30 \% \mathrm{w} / \mathrm{w}$ of paraffin. To establish a baseline, commercial PU was acquired and compared.

A series of tests with each one of the three synthesized fuel and the commercial PU were performed. The method of injection was axial to the grain, and the gaseous oxygen mass flow rate was kept constant at $40 \mathrm{~g} / \mathrm{s}$. The thrust results are presented in Fig. 5.

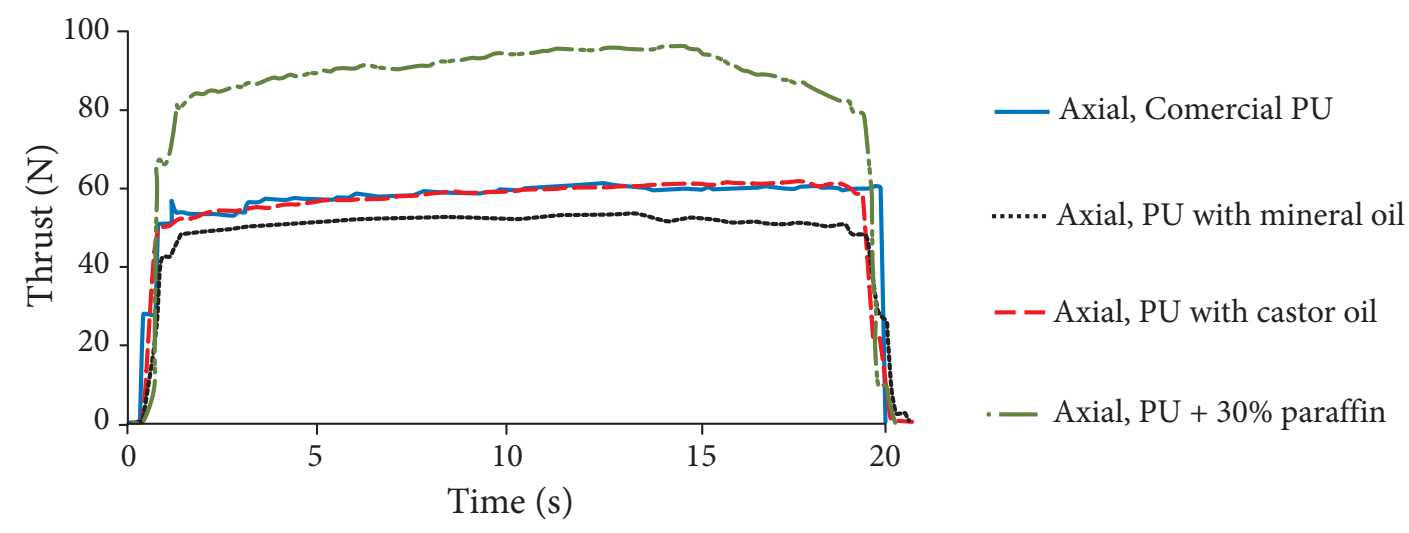

Figure 5. Thrust data of polymeric fuels and paraffin wax mixture with axial injector and 20-second tests. 
The graph shows that the PU synthesized with mineral oil yielded the lowest thrust, followed by commercial and PU synthesized with castor oil, both with the approximate thrust of $62 \mathrm{~N}$. Results obtained with the use of paraffin were the most promising reaching almost 100 N. Additional data are summarized in Table 1. Thrust presented the highest uncertainty of $4.9 \%$; other variables showed smaller uncertainties. The chamber pressure was calculated as the mean value of the plateau pattern obtained in the pressure curves.

It was observed that the binder that contained castor oil had better performance and higher stability. It increased $I_{\text {sp }}$ in about $15.6 \%$ and thrust in about $19.4 \%$. The addition of $30 \%$ paraffin increased $I_{\text {sp }}$ in about $29.5 \%$ and thrust in about $56.9 \%$ and the chamber pressure achieved with the same oxidizer mass flow rate is $58.8 \%$ higher. Regression rates in relation to the $\mathrm{PU}$ synthesized with castor oil increased almost $70 \%$. For the same oxidizer mass flow rate, pressure achieved was at least $70 \%$ higher when $30 \% \mathrm{w} / \mathrm{w}$ of paraffin was added.

The next step was increasing the percentage of paraffin. Unfortunately, there were temperature issues on the surface of the axial injector and on the case. The swirl injector was used, and the test duration was reduced to 6 seconds. The second series of tests was performed with PU also synthesized with castor oil in the following proportions:

- PU with $30 \%$ of paraffin

- PU with $30 \%$ of paraffin and $10 \%$ of aluminum (w/w)

- PU with $10 \%$ of aluminum
The results were the most promising so far; for more information, see Table 2.

The highest regression rate was achieved in the configuration of $30 \%$ paraffin and $10 \%$ aluminum; however the highest thrust was obtained when no aluminum was added (PU $+30 \%$ paraffin). Specific impulse was the lowest when aluminum powder was present and the highest when no aluminum was added to the fuel.

Previous analysis has shown that addition of aluminum to traditional hybrid solid fuels actually decreases the specific impulse because the molecular weight of the exhaust products is increased, which counteracts the raise in the temperature.

Figure 6 shows the steadiness of thrust achieved with PU with $30 \%$ of paraffin tested with the swirl injector. Average thrust values were about $23 \%$ higher than both grains with aluminum particles.

PU with $30 \%$ of paraffin ignites faster and presents the best performance. The other two cases show roughly the same constant thrust at about 88.9 N. Figure 7 shows a picture of the grain with $30 \%$ of paraffin after the firing test.

Paraffin melted and later suffered condensation; one could deduce that a motor with paraffin or any other liquefying fuel will work differently if restarted. Another effect observed in this series of tests was the contraction of the fuel grain after firings, which is a dangerous effect, once combustion can occur at the outer region of the grain and jeopardize the mission.

Table 1. Experimental results for each fuel using of the axial injector.

\begin{tabular}{|c|c|c|c|c|c|c|}
\hline Fuel & $\mathbf{P}(\mathbf{a t m})$ & $\mathbf{O} / \mathbf{F}$ & Thrust $(\mathbf{N})$ & $I_{\text {sp }}$ (s) & $\mathbf{r}$ (mm/s] & Injector \\
\hline PU + paraffin 30\% & 13.98 & 1.63 & 98.5 & 177.9 & 0.97 & Axial \\
\hline PU w/o castor oil & 8.11 & 3.72 & 52.7 & 121.1 & 0.50 & Axial \\
\hline PU with castor oil & 8.94 & 3.23 & 62.9 & 140.0 & 0.53 & Axial \\
\hline Commercial PU & 8.97 & 2.89 & 62.6 & 137.5 & 0.53 & Axial \\
\hline
\end{tabular}

Table 2. Experimental results for each test configuration.

\begin{tabular}{|c|c|c|c|c|c|c|}
\hline Fuel & $\mathbf{P}$ [ atm) & $\mathbf{0} / \mathbf{F}$ & Thrust $\mathbf{( N )}$ & $\boldsymbol{I}_{\text {sp }}$ (s) & $\mathbf{r}$ (mm/s] & Injector \\
\hline PU + paraffin 30\% & 17.65 & 2.63 & 108.8 & 140.0 & 2.63 & Swirl \\
\hline PU + 10\% Al & 13.86 & 3.23 & 88.9 & 88.9 & 3.29 & Swirl \\
\hline PU + 30\% paraffin + 10\% Al & 13.82 & 3.46 & 88.4 & 127.7 & 2.63 & Swirl \\
\hline
\end{tabular}




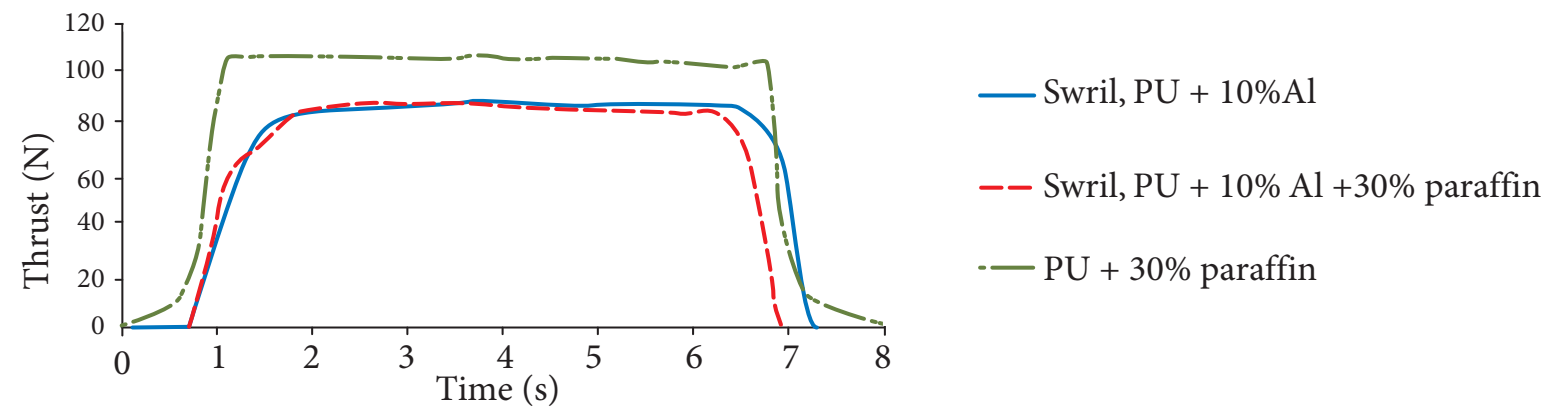

Figure 6. Thrust data of polymeric fuels and paraffin wax mixture with swirl injector and 6-second tests.

\section{ADDITION OF ALUMINUM AND GRAIN ANALYSIS}

Figure 8 shows the grain inside the stainless steel case prior to testing. This grain contains $10 \%$ of micron-sized aluminum powder and PU synthesized with castor oil.

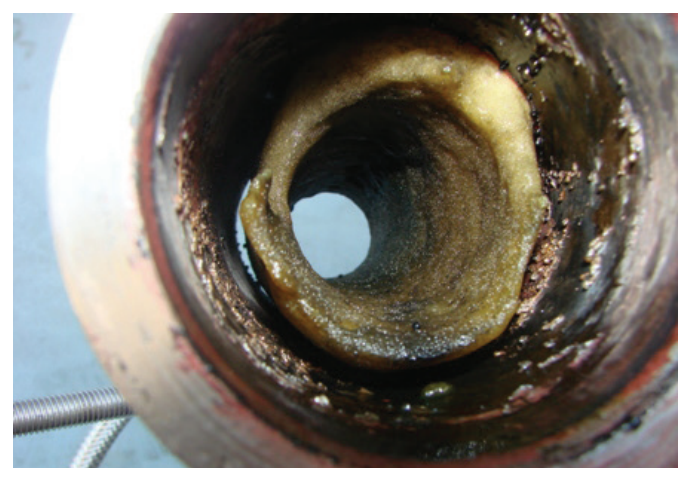

(a)

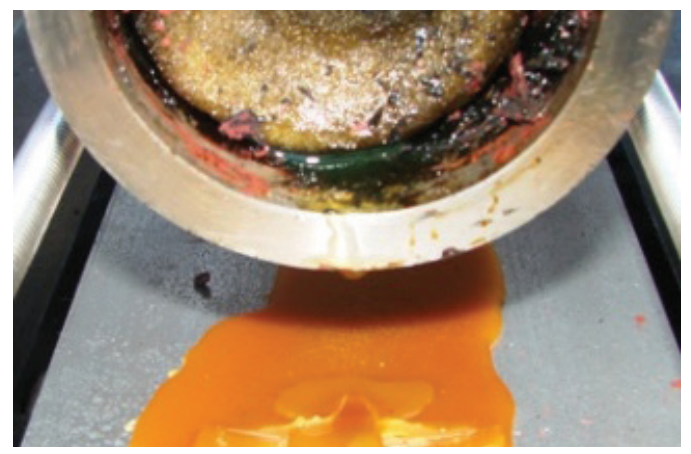

(b)

Figure 7. $\mathrm{PU}+30 \%$ of paraffin grain seen from the injector (a) and from the nozzle (b).
This particular grain was hard to ignite; two squibs were necessary to achieve ignition. It is supposed that the oxide layer on the surface is responsible for this problem, once the particles were not stored in an oxygen-free controlled environment.

Figure 9 shows the deposition of metallic aluminum on the rear section of the motor, around the nozzle.

Metallic powder was also deposited on the injector head, as can be seen in Fig. 10 .

It is evident that the aluminum deposition on several parts of the engine might cause problems; the most obvious is the accumulation of material close to the nozzle, once a possible throat obstruction is likely to occur. Even though the aluminum amount used was the same with or without the paraffin addition, the deposition when paraffin was present was less significant.

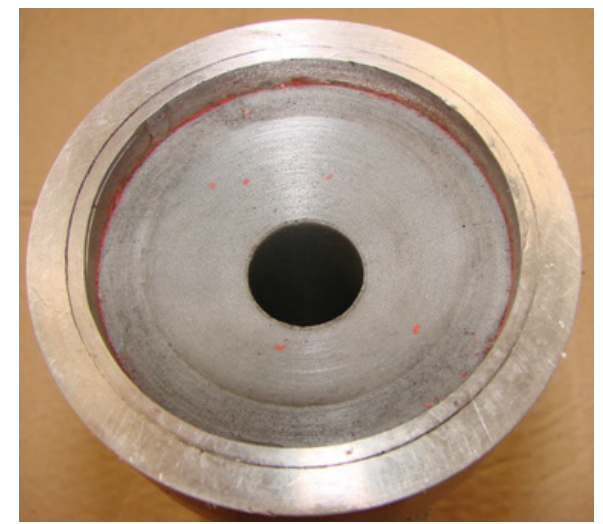

Figure 8. PU with $10 \%$ of micron-sized aluminum powder before testing. 


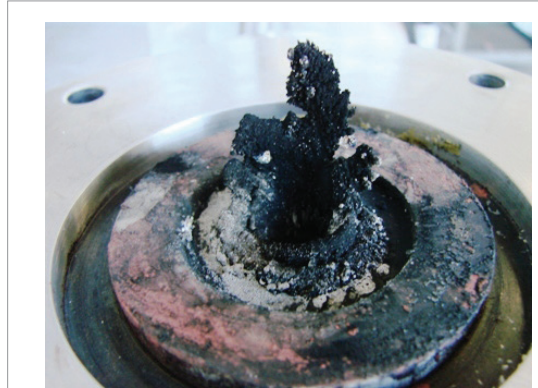

(a)

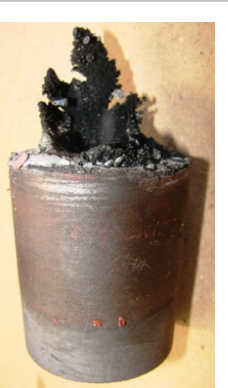

(b)
Figure 9. Deposition of aluminum powder around the nozzle.

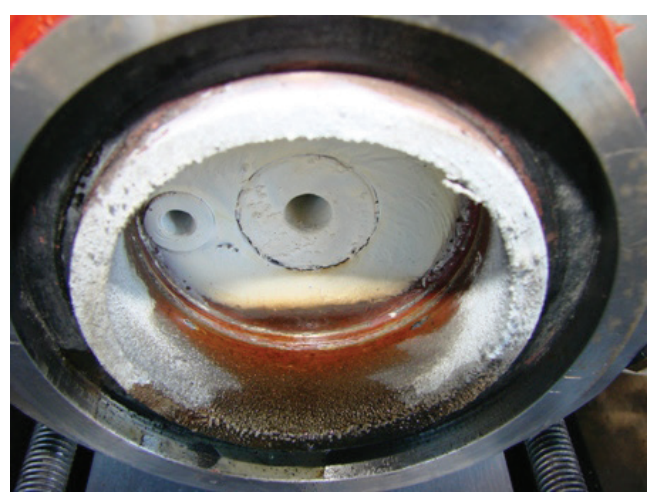

Figure 10. Deposition of aluminum powder on the injector.

\section{CONCLUSION}

The embedding of paraffin increased the overall ballistic parameters of the motor. The use of the binder is essential to structure and strengthen the paraffin to endure flight condition loads. Mixing ratios of $30 \% \mathrm{w} / \mathrm{w}$ of paraffin wax in the binder structure yielded good results, particularly when swirl injectors are used. Several additional tests must be performed to address the best mixing ratio. The aluminum particles probably presented an oxide layer too thick to participate in the combustion process. In future work, aluminum particles with smaller diameters and stored in controlled environments must be used.

\section{ACKNOWLEDGMENTS}

The authors gratefully acknowledge financial support from $\mathrm{CNPq}$ (Conselho Nacional de Desenvolvimento Científico e Tecnológico ) and AEB (Agência Espacial Brasileira).

\section{REFERENCES}

Altman, D., 2001, Rocket motors, hybrid. In Meyers, R.A. [Ed.], "Encyclopedia of Physical Science and Technology" (3rd ed., Vol. 14, pp. 303-321), Elsevier Science Ltd.

Altman, D. and Holzman, A., 2007, Overview and history of hybrid rocket propulsion, Progress in Astronautics and Aeronautics Series (1st ed., Vol. 218, p. 650). AIAA.

Altman, D. and Humble, R., 1995, "Hybrid Rocket Propulsion Systems", Space Propulsion Analysis and Design", in R. Humble, G. Henry, W. Larson (Eds.). McGraw-Hill, New York, pp. 365-441.

Boardman, T.A., 2001, "Rocket Propulsion Elements", In G.P. Sutton, John Wiley \& Sons.

Carmicino, C. and Russo Sorge, A., 2005, "Role of injection in hybrid rockets regression rate behavior", Journal of Propulsion and Power, Vol. 21, No. 4, pp. 606-612.

Carmicino, C. and Russo Sorge, A., 2007, "Performance comparison between two different injector configurations in a hybrid rocket", Aerospace Science and Technology, pp. 61-67.
Chiaverini, M., 2007, Review of solid-fuel regression rate behavior in classical and nonclassical hybrid rocket motors, in M.J. Chiaverini, K. K. Kuo (Eds.), "Progress in Astronautics and Aeronautics" (1st ed., Vol. 218, pp. 37-126), American Institute of Aeronautics and Astronautics.

Chiaverini, M., Serin, N., Johnson, D., Lu, Y.C., Kuo, K. and Risha, G., 2000, "Regression rate behavior of hybrid rocket solid fuels", Journal of Propulsion and Power, Vol. 16, No. 1, pp. 125-132.

Evans, B., Boyer, E., Kuo, K. K. and Risha, G., 2009, "Hybrid Rocket Investigations at Penn State University's High Pressure Combustion Laboratory: Overview and Recent Results", 45th AIAA/ASME/ SAE/ASEE Joint Propulsion Conference and Exhibit, AIAA Paper 2009-5349, Denver, Colorado, 2009.

Geisler, R.L., Frederick Jr, R.A. and Giarra, M., 2010, Historical overview and solid rocket motor fundamentals, in R. Blockley, W. Shyy (Eds.), "Encyclopedia of Aerospace Engineering" (Vol. 9), John Wiley \& Sons, Ltd. All rights reserved. 
Karabeyoglu, M.A. and Cantwell, B.J., 2002, "Combustion of liquefying hybrid propellants: part 2, Stability of liquid films", Journal of Propulsion and Power, Vol. 18, No. 3, pp. 621-630.

Karabeyoglu, M.A., Cantwell, B.J. and Altman, D., 2001 , "Development and Testing of Paraffn-Based Hybrid Rocket Fuels", in Proceedings of the 37th AIAA/ASME/SAE/ASEE Joint Propulsion Conference and Exhibit, July 2001, AIAA Paper 2001-4503.
Knuth, W.H., Chiaverini, M.J., Gramer, D.J. and Sauer, J.A., 1998, "Experimental Investigation of a Vortex-Driven HighRegression Rate Hybrid Rocket Engine", 34th AIAA/ASME/SAE/ ASEE Joint Propulsion Conference \& Exhibit. AIAA.

Risha, G.A., Evans, B.J., Boyer, E. and Kuo, K.K., 2007, Metals, energetic additives, and special binders used in solid fuels for hybrid rockets, in M. J. Chiaverini and K. K. Kuo (Eds.), "Progress in Astronautics and Aeronautics" (1st ed., Vol. 218, pp. 413456), American Institute of Aeronautics and Astronautics, Inc. 